\title{
The Effect of Process Improvement Practices on Manufacturing Competitiveness of Apparel Factories
}

\author{
Jared Ocampo ${ }^{1 *}$, Juan Hernández ${ }^{1}$, Juan Márquez ${ }^{1}$, Antonio Vizán ${ }^{1}$
}

\begin{abstract}
Process improvement practices (PIP) are being used as ways to improve manufacturing competitiveness (MC) but their overall effect in apparel factories have not been well quantified. This paper identifies the effects that PIP have on the manufacturing competitiveness of multinational apparel manufacturing plants. The methodology followed uses the Delphi method and exploratory factor analysis for variable selection, the Mann-Whitney test for analyzing the relationship between PIP usage and MC performance and regression analysis for estimating the existing correlation among the variables studied. The results show that factories with a high use of PIP have a higher manufacturing competitiveness and that specific practices related to error detection and waste elimination have a positive effect in cost, delivery time and environmental protection.
\end{abstract}

Keywords: textile industry; process improvement; competitiveness; multinational apparel factories; developing countries.

Submitted: June $26^{\text {th }}, 2019$ / Approved: May 11t ${ }^{\mathrm{h}}, 2020$

\section{Introduction}

The globalization of the economy has encouraged many companies to seek to improve their competitiveness by manufacturing their products in countries with cheap labor and then sell them in markets where they can get the highest selling price possible (Arora et al., 2004; Sarache et al., 2012). The arrival of the export-oriented manufacturing industry to emerging economies in Latin America has boosted greatly the manufacturing activity in these countries, generating direct employment and income to thousands of people of those communities (Balkwell \& Dickerson, 1994; Alonso, et al., 2002). However, the entry of Asia to the manufacturing production offering market requires that this industry in this part of the world rethinks its processes, and procedures to respond more quickly to customer needs and manufacture products of high quality and reliability at lower prices and in this way be more competitive and to stay in business (Mendoza, 2010).

Researchers have identified that the effective use of process improvement practices (PIP) such as TQM (total quality management), JIT (just in time), and Lean Manufacturing can help to increase the effectiveness and performance of companies (Swink \& Nair, 2007; Koc \& Bozdag, 2009). The effect of these tools in developed countries and in large industries such as metal-working, aeronautical and automotive is well researched and understood (Jonsson, 2000; Diaz et al., 2003; Contreras \& Carrillo, 2012). However, this is not the case in developing countries and particularly in the apparel assembly industry, where the effects of the use of PIP on manufacturing competitiveness (MC) are under-researched. Due to the prospect of great performance increment and the comparatively lower cost of implementation, PIP are being used in apparel factories in developing countries as ways to improve MC but without a clear understating of their overall and real effect. Hence, this paper seeks to identify the effects that process improvement tools, practices and methodologies (called PIP henceforth) have on the manufacturing competitiveness of multinational apparel manufacturing plants.

It is clear that the academic literature has a disproportional focus on developed economies and large industries (Sitompul, 2012; Ndiave et al., 2018), probably because the majority of the researchers come from those environments. However, the challenges of implementing improvement practices are different in developing countries and small and medium enterprises (SME) with less access to capital, educated workforce and other resources than those in developed nations and large companies (Prasad et al., 2005; Bülbül et al., 2013; Oliveira et al., 2017; Niebel, 2018; Pearce et al., 2018). Then, there is a clear need to carry out empirical research both in developing countries and SME in different topics. Therefore, the purpose of this study is to identify the effect that specific PIP have in helping to improve the MC of those companies. It is expected that this study will help managers of the apparel manufacturing industry be aware of which PIP are best suited to help them achieve improvements in specific capabilities.

\section{Theoretical background}

\subsection{Estimating competitiveness at the company level}

Although there is not a definition of competitiveness that is universally accepted, company or firm competitiveness can be thought as a company's ability to perform better than similar companies in terms of sales, profitability, quality, efficiency, among others (Lall, 2001). To achieve this level of performance, the company needs to attain a higher degree of specialization or excellence in certain areas in comparison with those it competes against (De Carolis, 2003). Although some authors advocate the use of only financial performance indicators to measure competitiveness (Lall, 2001; Magretta, 2012), the factors that lead a company to being competitive usually are non-financial. In fact, many authors argue that a better way to measure a company's competitive advantage in the marketplace is by assessing its ability to

(1) Universidad Politécnica de Madrid, Mechanical Engineering Department, Madrid, Spain.

*Corresponding author: jared.ocampo@unitec.edu

ISSN: 0718-2724. (http://jotmi.org)

Journal of Technology Management \& Innovation ( ) Universidad Alberto Hurtado, Facultad de Economía y Negocios. 
achieve its manufacturing goals (or priorities), which is through its manufacturing capabilities (Barney, 1991; Hanson et al., 2012; YungChing \& Tsui-Hsu, 2006; Zollo \& Winter, 2002; Santos-Vijande \& Álvarez-González, 2009). In fact, some authors have found a positive relationship between high levels of competitive capabilities and achieving a high-level performance (Tan et al., 2007).

In the literature, manufacturing goals or competitive priorities are strategic choices about which capabilities are important to achieve certain expected outcome (Leong et al., 1990; Avella et al., 2001). Likewise, the performance of a company in its competitive priorities relative to its competitors is known as the firm's competitive capabilities (Ward et al., 1998). Since these priorities/capabilities are multidimensional by nature, a group of components or dimensions explain or help to measure each priority/capability, which may vary depending on the industry under study. Since it is impossible to excel in all these priorities/capabilities simultaneously (Fine \& Hax, 1985), a balance or trade-off between them must be established. The level of importance of each of them and their components can be obtained using empirical analysis of the perception of company directors, vice presidents, or managers (Rostek, 2012; Awwad et al., 2013) or expert opinion (Sarache et al., 2012).

For instance, in a study by Ocampo et al. (2017), factory's MC was measured in an aggregated way by using the weighted mean of scores obtained regarding the factories' comparative performance (capabilities) in different factors with an adjustment done using the importance (priorities) that each of those factors has in their respective industrial sector. The study found that the MC for apparel factories in Central America had four main factors or capabilities: cost, environmental protection, delivery time and flexibility, with 13 disaggregated components. The authors also found that the reason why quality does not appear as a competitive priority for this industry is because managers consider it an integral part of their operations, one of their core competences. The methodology developed and the results obtained are interesting and relevant to this study.

\subsection{Process improvement practices (PIP) and competitiveness}

The resources that companies have nowadays available to improve their manufacturing performance can be categorized in two major groups: manufacturing technologies and manufacturing methodologies (Khanchanapong et al., 2014; Bortolotti et al., 2015). Technologies refer to hardware and computer programs (software) used to design, produce, and control; while methodologies refer to practices, procedures, techniques, and knowhow used to manage and improve. Since the high cost of most of these technologies (hardware and software) makes its implementation almost prohibitive for companies seeking for inexpensive labour force, an alternative for improving manufacturing performance is using process improvement methodologies, which in theory are less expensive to implement and better suited for labour-intensive apparel manufacturing factories.

In the 1980s and early 1990s, a group of improvement methodologies focused on enterprise operations and process improvement were introduced into the manufacturing industry. Lean Enterprise System, an evolution of Just-In-Time (JIT), is a management model which was designed to create workplaces that are more efficient by reducing waste and non-value-added activities (García et al., 2014). Other similar philosophies include Total Quality Management (TQM), which seeks to foster a climate of continuous improvement by seeking quality on their products and services based on understanding the expectations of its customers (Padhi, 2015), and Six Sigma whose primary goal is to ensure continuous improvement by reducing all sources of unwanted process and product variability (Hernández \& Vizán, 2013). Several studies have identified TQM, JIT (Flynn et al., 1995; Clark, 1996) and Lean Manufacturing (Fullerton \& Wempe, 2009; Yang et al., 2011; van Assen, 2018) as best practices used to obtain superior performance. Those methodologies are comprised of different practices that sometimes overlap between philosophies and which in some cases are complementary to one another (Khanchanapong et al., 2014). Table 1 shows some of those practices listed in the literature.

Table 1. PIP with an influence in operational performance.

\begin{tabular}{|c|c|}
\hline Authors & PIP used to improve operational performance \\
\hline Sureerattanan et al. (2014) & $\begin{array}{l}\text { Supplier feedback, Just-in-time delivery, Developing suppliers, Involved customers, Pull, Continuous flow, Low setup, Controlled } \\
\text { processes, Productive maintenance, Involved employees }\end{array}$ \\
\hline Laohavichien et al. (2013) & Setup time reduction, Cellular manufacturing, Quality improvement, Process innovation, Product \& Service innovation \\
\hline Alsmadi et al. (2012) & $\begin{array}{l}\text { Supplier feedback, JIT delivery by suppliers, Supplier development, Customer involvement, Pull, Continuous flow, Set-up time re- } \\
\text { duction, TPM, SPC, Employee involvement }\end{array}$ \\
\hline Hana Arrfou et al. (2016) & TQM practices, LM practices \\
\hline Yang, Hong \& Modi (2011) & JIT Flow, Quality Management, Employee Involvement, Environmental Management Practices \\
\hline Khanchanapong et al. (2014) & Production flow management, Customer focus, Process management, Workforce management, Supplier management \\
\hline Green et al. (2014) & Total JIT, Supply chain management strategy \\
\hline Bortolotti et al. (2015) & $\begin{array}{l}\text { Small group problem solving, Training employees, Top management leadership for quality, Supplier partnership, Customer involve- } \\
\text { ment, Continuous improvement, JIT delivery by suppliers, Equipment layout for continuous flow, Setup time reduction, Statistical } \\
\text { process control, Kanban, Autonomous maintenance }\end{array}$ \\
\hline Belekoukias et al. (2014) & Just-in-time, Total productive maintenance, Autonomation, Value stream mapping, Kaizen/continuous improvement \\
\hline Panwar et al. (2018) & $\begin{array}{l}\text { Supplier rationalization, Long term relationship, Supplier integration and partnership, Visual control, Quality control, JIT purchasing, } \\
\text { Quick changeover techniques, Lot-size reduction, Bottleneck/constraint removal, 5S, Total productive maintenance, Statistical process } \\
\text { control, Work standardization, Flexible and cross-functional teams, New equipment and technology, Continuous improvement programs }\end{array}$ \\
\hline Zeng et al. (2015) & Small group problem solving, Employee suggestion, Task-related training for employees, Quality information, Process management \\
\hline Ocampo et al. (2017) & $\begin{array}{l}\text { Kaizen events, TPM (total productive maintenance), VSM (value stream map), SMED (single minute exchange die), Kanban, TQM } \\
\text { (total quality management) }\end{array}$ \\
\hline
\end{tabular}


The impact that these methodologies have on the different capabilities that define MC have been discussed in prior studies. For instance, JIT has been associated with superior performance in quality, lead-time, productivity and customer service (Lawrence \& Hottenstein, 1995), but has not shown significant associations with cost efficiency and flexibility (Flynn et al., 1999). On the other hand, TQM shows positive associations with cost efficiency and flexibility (Flynn et al., 1999). In the case of Lean practices, these have been positively associated with cost and lead-time reduction, along with enhancements in quality and flexibility performance (Vinodh \& Joy, 2012; Khanchanapong et al., 2014). The result of these studies anticipates that not all PIP will affect in the same way the different manufacturing capabilities of the apparel factory industry.

\subsection{Hypotheses development}

Although the advocates of different PIP promise great benefits for its implementation, empiricial evidence does not always validate these claims (Swink \& Nair, 2007). For instance, large companies tend to have higher PIP investments than smaller ones, but with a seemingly non-existing correlation between PIP use and firm performace (Salegna \& Fazel, 1995; Swamidass \& Kotha, 1998; Jonsson, 2000; Diaz et al., 2003). However, this is different for small and medium sized enterprises (SME), where there is a better correlation between PIP use and operational performance (Koc \& Bozdag, 2009). In fact, the relationship between PIP use and firm performance seems to be related to company size and type of activity (Diaz et al., 2003). Additionally, since the apparel manufacturing industry is very labor-intensive, it is expected that the use of improvement methodologies or technological tools will improve significantly its competitiveness (Putranto et al., 2003), hence the following hypothesis is proposed:

H1: Apparel manufacturing factories with a higher use of PIP exhibit a higher MC performance than those with a lower use of PIP.

Companies use PIP in order to eliminate waste, assure quality, enhance efficiency, reduce variability, detect and solve problems (Mohd Hame et al., 2017), as well as to improve significantly their performance. Performance is measured in terms of competitive capabilities, namely cost, quality, delivery time, flexibility and environmental protection, hence the use of the "MC performance" concept. Literature shows that there are many different PIP that can be used to achieve these purposes, although, some are more aligned with achieving specific capabilities than others (Pavnaskar et al., 2003). However, using these PIP by themselves will not be as useful as using them as a set or in a complementary way (Khanchanapong et al., 2014). For instance, the use of VSM, 5-S and Kaizen, which are aligned with waste elimination, have shown to create efficient production layouts and reduce scrap which improve production flow speed, delivery time and efficiency, as well as reduce lead-time, cost and scrap waste (Ward \& Zhou, 2006; Vinodh \& Joy, 2012). Then, the following is hypothesized:

H2 $\boldsymbol{a}$-d: The use of waste elimination PIP affects positively the quality, cost, delivery time and environmental protection capabilities of apparel manufacturing factories.
Normally quality assurance PIP such as TQM and SPC are used to improve the quality of goods and services. Then, the use of tools such as Pareto, scatter and pie charts, along with the use of statistical techniques for monitoring and controlling the quality of the processes and outputs help to develop a better quality performance (Flynn et al., 1995; Swamidass, 2003) and corporate competitiveness (Lee \& Choi, 2006). However, they also affect other capabilities as indicated by Vinodh \& Joy (2012), who reported that TQM, JIT, and Lean show a positive impact in quality performance, cost reduction and efficiency production, specially when these PIP are used in connection with workforce commitment to resolve observed problems (Yeung et al., 2006). Based on the above the following hypothesis is presented:

$\boldsymbol{H} \mathbf{3} \boldsymbol{a}$-b: The use of quality assurance PIP affects positively the quality and cost capabilities of apparel manufacturing factories.

The use of time reduction PIP such as Kanban and SMED has proven to help enhance the flexibility of manufacturing plants due to their increase ability to work with smaller batches because of fast equipment changeover (Chang et al., 2005). The setup time reduction also decreases lead time which directly impacts cost and delivery time (Alsmadi et al., 2012). The use of other related PIP such as pull systems and cellular flow increases throughput and reduces work-in-process inventory (Lee \& Ebrahimpour, 1984; Swink et al., 2005) which not only positively affects flexibility, delivery time and cost, but also reduces energy consumption and waste. Then the following hypothesis is proposed:

$\boldsymbol{H} 4 \boldsymbol{a}-\boldsymbol{d}$ : The use of time reduction PIP affects positively the flexibility, cost, delivery time and environmental protection capabilities of apparel manufacturing factories.

Error detection PIP such as poka-yoke, Jidoka and FMEA allow to detect, analyze and correct defects in design, on machinery, and in manufacture or assembly (Geum et al., 2011; Kudlác et al., 2017). The appropiate use of these practices not only helps to assure quality (Angelis et al., 2011), but also improves efficiency and reduce waste associated with time delays. The creation of mistake-proof solutions and the prioritization of failures and their corresponding actions require cross functional teams that understand well the processes so they can find the appropiate balance between cost, quality and delivery time (Keller, 2012). The direct involvement from the workforce has been reported to help enhance their skills so they can perform their tasks more efficiently, improving productivity and reducing costs (Swink et al., 2005). Therefore the following hypothesis can be proposed:

H5 $\boldsymbol{a}-\boldsymbol{d}$ : The use of error detection PIP affects positively the quality, delivery time, cost and environmental protection capabilities of apparel manufacturing factories. 


\section{Research design and methodology}

\subsection{Data analysis procedure}

As it can be seen in Figure 1, this study followed a mixed design method with an inductive qualitative part to determine which PIP to use and how to measure $\mathrm{MC}$, and a deductive quantitative part used to collect and analyse empirical data. The overall methodology is composed of three main steps:

Figure 1. Data analysis procedure for finding the relationship between PIP and MC

\section{Step 1: Identify the variables to study}

1. Identify all PIP and MC components available in the consulted literature.

2. Expert analysis to select those tools and elements that are representative and applicable to the industry under study.

3. Preparation of cross-sectional survey to collect empirical data for in depth analysis.

Step 2: Establish the models to analyze
1. Collect data from a survey applied to managers and
engineers of the industry under study.
2. Find constructs (latent variables) to establish models of
PIP and MC using EFA.
3. Estimate the MCS and individual CS.
Step 3: Find relationships and validate hypotheses
1. Test H1 with a Mann-Whitney test to analyze the
relationship between PIP usage and MCS performance
2. Test H2 - H5 with a Person correlation and regression
analysis to find the relationships between PIP and CS.
3. Validate the proposed hypotheses and present overall
results and conclusions of the study.

Step 1: Identify the variables to study

A list of tools and practices used for process improvement within the factory and of capabilities used to achieve manufacturing competitiveness was gathered from a comprehensive literature review. The discrimination and subsequent selection of the variables to study was done using the opinion of experts from industry and academia through the Delphi method (Scott, 2000). From the final list of PIP and capabilities obtained from experts through Delphi, a survey was created and sent to plant, production and engineering managers in order to collect empirical data to be used in the subsequent steps.

\section{Step 2: Establish the models to analyse}

Since the main objective of the study was to measure the effects of PIP on MC, it was necessary to establish structured models that grouped the selected elements logically. Different researchers in operation management have used Exploratory Factor Analysis (EFA) to take large numbers of seemengly unrelated variables and discover underlying or latent variables to help them define better models (Jun et al., 2006; Pinjala et al. 2006). Therefore, EFA was used to discover the PIP correlated variables (factors) using the sampled data. Using the model and the survey responses it was possible to estimate PIP usage, as well as the combined manufacturing competitiveness score (MCS) and the individual capabilities scores (CS) of the sampled plants.
Step 3: Find relationships and validate hypotheses

To test $H 1$ it is necessary to estimate the use of PIP and the MCS of the apparel manufacturing factories. Since the sample used in this study is relatively small, the existence of significant differences in the factories' MC with respect to PIP's was tested through the Mann-Whitney test for independent samples, which is a non-parametric test (García-Muiña \& Navas-López, 2007). This was done by dividing the sampled factories in two groups: low and high performers, and then using the Mann-Whitney test to see if the PIP's use was significantly different between them. To test the other hypotheses $(\mathrm{H} 2-\mathrm{H} 5)$ it was required to measure the causeeffect relationship between the different groups of practices (PIP factors) and the improvement in specific competitive capabilities (measured as CS) using regression analysis (Cohen, 1988). A linear regression analysis between each PIP and MC factor was used to find the strength of the relationship between the variables (correlation) and the effect of that relation (coefficient of determination). The strength of the effects was interpreted using Cohen's (1988) conventions as summarized in Table 2.

Table 2. Strength of the correlation and regression effects.

$\begin{array}{ccc}\text { Effect Size } & & \\ \text { Large } & 0.50 & 0.25 \\ \text { Medium } & 0.30 & 0.09 \\ \text { Small } & 0.10 & 0.01\end{array}$




\subsection{Sample and data collection}

To test the proposed hypotheses, an empirical study was conducted using apparel manufacturing factories located in Honduras, which is a good example of a small emerging economy from Central America with strong multinational plants. According to the Honduran Central Bank (BCH), there are 122 apparel manufacturing companies in Honduras, each of them with several manufacturing plants, most of them located in the northern part of the country (BCH, 2014). The survey was sent to plant, production and engineering managers, which are the most experienced people for this type of studies (Bülbül et al., 2013; Khanchanapong et al., 2014). 228 apparel manufacturing plants were surveyed, and 98 responses were obtained, with 57 being usable (all items were answered). These managers assessed their factory's use of PIP and their comparative performance in the competitive capabilities using a survey designed to be completed online (www.qualtrics.com).

Regarding the demographics of the study it must be noted that $70 \%$ of the sampled plants were multinational companies whose managers had experience working in similar factories in Central America and the Caribbean. $15 \%$ of the respondents had more than 20 years of experience, $32 \%$ had between 10 and 20 years, $21 \%$ between 5 and 10 years, and the rest less than 5 years of experience. Additionally, $58 \%$ of the respondents worked on plants with more than 1000 people. These demographics are important as it shows that the sample is representative of this industry, giving consistency to the results of the study. Additional to the demographic questions, the survey used a five-point Likert scale to assess PIP use and the comparative MC of the apparel manufacturing plants. PIP use was evaluated by asking respondents regarding the degree of use given to each PIP ranging from (1) not used, to (5) it is always used. Respondents were also asked to assess their comparative performance in different capabilities ranging from (1) significantly lower than competitors, to (5) significantly better than competitors.

\subsection{Reliability of the instruments and constructs}

Since the measures being used were obtained from a panel of experts that used well-established empirical and conceptual elements drawn from literature review, the content validity of the study can be inferred (Bohrnstedt, 1983). However, to assess the reliability and internal consistency of the survey, a Cronbach's alpha test was performed obtaining a 0.88 for the MC section and 0.86 for the PIP section, with alpha values for each construct above the 0.7 threshold (Nunnally \& Bernstein, 1994). The PIP data was subjected to an exploratory factor analysis (EFA) to find if the proposed practices could be grouped into correlated constructs. The factoring method used was principal component analysis (PCA) with a varimax rotation and the extraction based on Eigenvalues greater than 1. The appropriateness of the dataset to perform the required EFA was confirmed with a KaiserMeyer-Olking (KMO) test of 0.72, which was above the 0.6 suggested threshold value (Sharma, 1996). The significance of the model was verified through the Bartlett's sphericity test (Pinjala et al., 2006). The items with high factor loadings (above 0.5 ) were retained and the rest were discarded to assure convergence and discriminant validity.

\section{Results and discussion}

\subsection{PIP measurement model}

As shown in Table 3, an EFA was conducted in the PIP data according to the previously described methodology (step 2) which yielded a four-factor model or categorization with 15 disaggregated components that could explain $65 \%$ of all the variance.

Table 3. Results from EFA for the PIP.

\begin{tabular}{|c|c|c|c|c|c|c|}
\hline Process Improvement Practices & Mean & $S D$ & Waste Elim. & Time Reduct. & Quality Assur. & Error Detect. \\
\hline \multicolumn{7}{|l|}{ WE - Waste elimination (Cronbach's alpha $=0.83$ ) } \\
\hline WE1 - 5S (workplace organization method) & 4.54 & 0.85 & 0.774 & 0.130 & 0.137 & 0.008 \\
\hline WE2 - Kaizen events (VSM, 5S, SOP, Visual factory) & 4.46 & 0.96 & 0.749 & 0.331 & 0.242 & -0.084 \\
\hline WE3 - TPM (Total productive maintenance) & 4.33 & 1.21 & 0.707 & 0.381 & 0.293 & 0.078 \\
\hline WE4 - VSM (value stream map) & 4.25 & 0.95 & 0.659 & 0.191 & 0.471 & 0.162 \\
\hline WE5 - ANDON (alarm warnings and signals) & 4.04 & 1.34 & 0.644 & -0.184 & -0.012 & 0.420 \\
\hline \multicolumn{7}{|l|}{ TR - Time reduction (Cronbach’s alpha = 0.75) } \\
\hline TR1 - Cellular flow & 4.33 & 1.11 & -0.066 & 0.778 & 0.051 & 0.277 \\
\hline TR2 - Standard operating procedure (SOP) & 4.79 & 0.59 & 0.201 & 0.715 & 0.093 & 0.034 \\
\hline TR3 - Kanban (pull system) & 4.61 & 0.73 & 0.386 & 0.649 & 0.201 & -0.024 \\
\hline TR4 - AMT (analytical method training) & 4.33 & 1.18 & 0.213 & 0.618 & 0.167 & -0.053 \\
\hline TR5 - SMED (single minute exchange die) & 4.37 & 1.01 & 0.309 & 0.590 & -0.109 & 0.100 \\
\hline \multicolumn{7}{|l|}{ QA - Quality assurance (Cronbach's alpha $=0.79$ ) } \\
\hline QA1- SPC (Statistical process control) & 4.63 & 0.84 & 0.085 & -0.058 & 0.913 & 0.084 \\
\hline $\begin{array}{l}\text { QA2 - TQM (Total quality management) - Ishikawa, } \\
\text { Pareto, Flow diagram, Brainstorming, Focus group } \\
\text { Histogram, Scatter diagram, Bar graph, Pie chart }\end{array}$ & 4.61 & 0.70 & 0.260 & 0.239 & 0.761 & 0.025 \\
\hline QA3 - TMM (Time measurement method) & 4.68 & 0.63 & 0.176 & 0.433 & 0.616 & 0.138 \\
\hline \multicolumn{7}{|l|}{ ED - Error detection (Cronbach's alpha = 0.74) } \\
\hline ED1 - FMEA (Failure mode and effect analysis) & 3.42 & 1.35 & -0.107 & 0.040 & 0.064 & 0.844 \\
\hline ED2 - Jidoka - (autonomation of error detection) & 2.84 & 1.60 & 0.215 & 0.217 & 0.132 & 0.761 \\
\hline Total Variance & & & 2.889 & 2.362 & 1.727 & \\
\hline$\%$ of Variance & & & 18.296 & 15.099 & 11.785 & \\
\hline Cumulative \% & & & 38.546 & 53.645 & 65.430 & \\
\hline
\end{tabular}


Taking into consideration the main purpose of the grouped practices, the names given to the discovered PIP factors were waste elimination, time reduction, quality assurance and error detection. From the EFA results it is evident that managers and engineers consider that some practices could only be effective when used together as a set of complementary practices such as SPC and TQM, while others could be used as separate practices such as those comprising JIT (Kaizen events, 5-S, Kanban, SMED, etc.). Hence, some of the practices that make up the JIT methodology are distributed between the waste elimination and time reduction factors, while practices comprising methods engineering are split between the time reduction and quality assurance factors. This shows the versatility of the techniques that are part of the JIT and methods engineering methodologies. From these results it looks like in this particular industry SOP, which is normally used to improve quality (e.g. ISO 9001), it is used to reduce time, and that VSM, which is normally used to show the process' idle time, it is used to help eliminate waste.

Although some of the initially proposed practices had to be dropped from the PIP model, their benefits are still present in this industry due to the considerable overlap between the methodologies. For instance, DMAIC, which is a very popular tool for process improvement from Six Sigma was dropped from the final model due to their low loadings in the EFA model. However, this does not mean that the tool is not used, it might just mean that those being surveyed considered that the steps of that methodology (define, measure, analyse, improve and control) were already taken into consideration in other practices such as Kaizen, SPC and TQM.

\subsection{MC measurement model}

The MC was estimated using the method proposed by Ocampo et al. (2017) and the survey results with the following equation:

$M C=\left(0.268{ }^{\star}\right.$ Cost $)+\left(0.254{ }^{\star}\right.$ Env. Prot. $)+\left(0.241{ }^{\star}\right.$ Deliv. Time $)+$ $\left(0.237^{\star}\right.$ Flexibility $) \quad(1)$

Where

Cost $=[(0.848 *$ Increase installed capacity utilization $)+(0.831 *$ Increase labour productivity $)+(0.799 *$ Increase production efficiency $)+(0.573 *$ Increase compliance to product specification $)]$ / $(0.848+0.831+0.799+0.573)$

Env. Prot. $=[(0.860 *$ Prevent environmental incidents $)+(0.784 *$ Use of production processes environmentally friendly $)+(0.778 *$ Provide the firm with a positive environmental image $)] / \quad(0.860+0.784+$ 0.778)

(3)
Deliv. Time $=\left[\left(0.889{ }^{*}\right.\right.$ Reduce manufacturing time $)+(0.680 *$ Reduce lead time (total production time $))+(0.652 *$ Reduce time or cost of preparation and changeover $)] /(0.889+0.680+0.652)$

Flexibility $=\left[\left(0.904{ }^{\star}\right.\right.$ Reduce time to introduce a new product $)+(0.846$ * Ability to introduce new products $)+(0.658 *$ Rapid changes from one product to another $)] /(0.889+0.846+0.658)$

This model is consistent with the literature, as four of the five typical competitive priorities are present in the model (Avella et al., 2001; 2011; Greasley, 2009). However, quality is not present in the model, probably because clients in this particular industry only contract companies with proven high quality. An evidence of this is the fact that when these companies accept a manufacturing job, they make tests and previsions to make sure they can achieve the required quality specifications before starting production, so their cost does not increase by reprocessing the garments that do not meet the agreed quality. Hence, apparel manufacturing managers might consider quality an integral part of their operations.

\subsection{The effect of PIP use in MC}

The MCS of each apparel manufacturing plant in the sample was estimated using equation 1, and the results were separated in two groups: low performers $(\mathrm{MCS}<4)$ and high performers $(\mathrm{MCS} \geq$ 4), where 4 represents an $80 \%$ performance. As shown in Table 4 , factories with a high use of PIP (frequently used or always used) had also a high performance, in contrast to those with a lower use (not used or sometimes used). To validate this conclusion, a non-parametric Mann-Whitney test was performed using the two groups and the average usage value of each PIP to test the hypothesis that apparel manufacturing factories with a higher use of PIP exhibit a higher MC performance (level of MC). The result of the test yielded a $p$-value $=0.012(p<0.05)$ meaning that both groups are significantly different, confirming that the tool usage for the high performing group is higher than the usage for the low performing group. Then Hypothesis 1 cannot be rejected, which means that apparel manufacturing factories with a higher use of PIP exhibit a higher MC. This was consistent with previous findings that show a positive correlation between company operational performance and AMT use (Putranto et al., 2003; Koc \& Bozdag, 2009). 
Table 4. Use of PIP in multinational apparel factories by company performance.

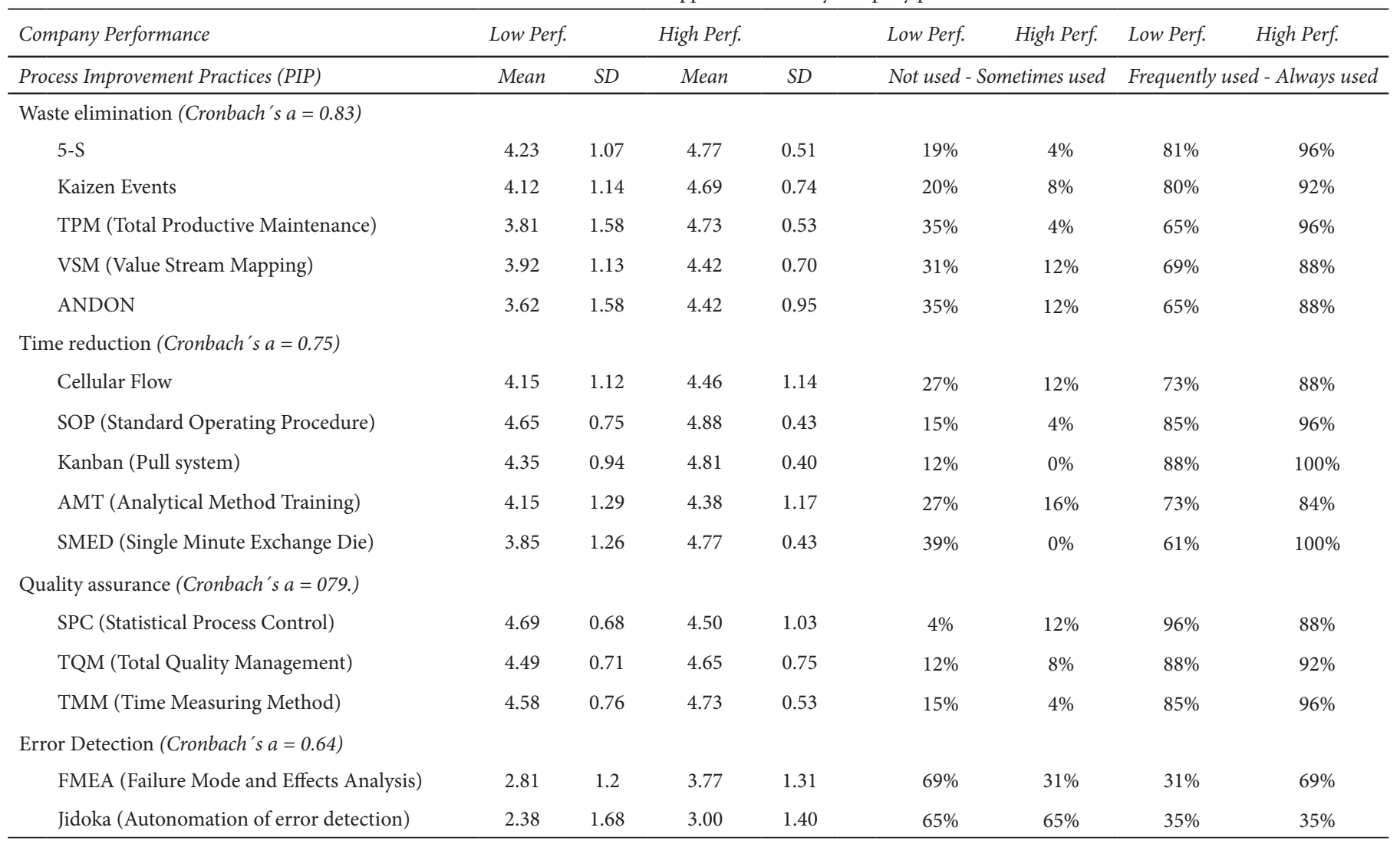

\subsection{The effect of the PIP factors on the MC factors}

To identify the existing relationships between PIP and MC, a regression analysis was performed using the PIP model factors as independent variables and the MC model factors as dependent variables. The latent variable values from the PIP model were obtained from the survey's respondents averages values and those of the MC model came from solving Equations 2 through 5. The sample used
(57), was considered appropriate as for regression analysis David (2009) suggested a $n \geq 25$ and Green (1991) recommended a minimum sample of $50+8 m$, where $m$ is the number of predictors (for linear regression analysis $m=1$ ). Table 5 shows the correlations and regressions values (relationship and effect sizes) that were significant $(p<0.05)$ shown in bold. All the calculations were done using IBM SPSS V.22.

Table 5. Pearson correlation and regression analysis between PIP and MC.

\begin{tabular}{|c|c|c|c|c|c|}
\hline Independent Variables & Dependent Variables & & & $F$ & Sig \\
\hline \multirow{4}{*}{$\begin{array}{c}\text { Error } \\
\text { Detection }\end{array}$} & Delivery Time & 0.346 & 0.120 & 7.502 & 0.008 \\
\hline & Cost & 0.308 & 0.095 & 5.765 & 0.020 \\
\hline & Env. Protection & 0.263 & 0.069 & 4.097 & 0.048 \\
\hline & Flexibility & 0.224 & 0.050 & 2.897 & 0.094 \\
\hline \multirow{4}{*}{$\begin{array}{c}\text { Time } \\
\text { Reduction }\end{array}$} & Delivery Time & 0.244 & 0.060 & 3.489 & 0.067 \\
\hline & Cost & 0.276 & 0.076 & 4.532 & 0.038 \\
\hline & Env. Protection & 0.338 & 0.114 & 7.012 & 0.010 \\
\hline & Flexibility & 0.221 & 0.049 & 2.832 & 0.098 \\
\hline \multirow{4}{*}{ Quality Assurance } & Delivery Time & 0.146 & 0.021 & 1.206 & 0.277 \\
\hline & Cost & 0.035 & 0.001 & 0.068 & 0.795 \\
\hline & Env. Protection & 0.078 & 0.006 & 0.337 & 0.277 \\
\hline & Flexibility & 0.031 & 0.001 & 0.052 & 0.820 \\
\hline \multirow{4}{*}{ Waste Elimination } & Delivery Time & 0.465 & 0.216 & 15.188 & 0.000 \\
\hline & Cost & 0.374 & 0.140 & 8.928 & 0.004 \\
\hline & Env. Protection & 0.438 & 0.192 & 13.039 & 0.001 \\
\hline & Flexibility & 0.220 & 0.048 & 2.803 & 0.100 \\
\hline
\end{tabular}


The results of the regression analysis show that when PIP dedicated to waste elimination (5-S, Kaizen, TPM, VSM, and Andon) are used together in apparel manufacturing factories, they have a significant positive effect in improving cost (0.14), delivery time (0.22) and environmental protection (0.19). According Cohen (1988) all these effects range from medium to large size (Table 2). Then Hypotheses $2 b, 2 c$ and $2 d$ cannot be rejected, meaning that waste elimination PIP affects positively the cost, delivery and environmental protection capabilities of the apparel manufacturing factories. These results are partially consistent with the findings of Vinodh \& Joy (2012). Since quality is not a competitive priority of this industry because managers consider it an integral part of their operations, one of their core competences (Ocampo et al., 2017), Hypothesis $2 a$ was rejected.

The regression analysis also shows that none of the practices dedicated to quality assurance (SPC, TQM and TMM) have any significant effects with the MC factors, therefore Hypotheses $3 a$ and $3 b$ were rejected. The lack of correlation between these practices and the MC factors might be a reflection of this industry managers' perception that quality is an integral part of their operations and one of their core competences. Due to this, managers might not see necessary to point out the use of specific PIP to assure quality, as their day-to-day processes have imbedded mechanisms to assure the required quality. However, since these results contradict theory, it requires a more indepth review in future studies.

In the case of time reduction practices (cellular flow, SOP, Kanban, AMT and SMED), the regression analysis shows that when used together, these PIP have a significant positive effect in improving cost (0.08) and environmental protection (0.11). The size of these effects' ranges from small to medium (Table 2) therefore, Hypotheses $4 b$ and $4 d$ cannot be rejected. This means that time reduction PIP affects positively the cost and environmental protection capabilities of the apparel manufacturing factories. These results are partially consistent with previous findings by Swink, et al. (2005) and Ward \& Zhou (2006). However, it was contra intuitive to see that time reduction PIP did not show significant effects on improving flexibility or delivery time, rejecting Hypotheses $4 a$ and $4 c$.

In the case of flexibility, it must be remembered that this competitive capability is related to the ability to react to changes in product type, mix and volume, and in general terms plants in this industry only demand incremental adjustments in their machine utilization and capacity, layouts, and labour force training. Then, a possible reason for this lack of correlation could be that plants in this industry do not regularly deal with the introduction of new products with radical changes as in other industries, or that these flexible requirements are handled by specialized plants dedicated to these situations.

In the case of delivery time, it is interesting to note that the practices that presented a connection with improving delivery time are those that help reduce the reprocessing of garments (error detection and waste elimination). Therefore, a reason for this striking lack of connection might be that the main problems associated with missing delivery dates are not associated with accelerating production or improving the product flow, but with eliminating reprocess. However, since these results contradict theory, it will also require a more indepth review in future studies.

Finally, the performed analysis shows that when practices dedicated to error detection such as FMEA and Jidoka are used together they have a significant positive effect in improving cost (0.09), delivery time (0.12) and environmental protection (0.07). These effect sizes range from small to medium (Table 2) then, Hypotheses $5 b, 5 c$ and $5 d$ cannot be rejected, meaning that error detection PIP affect positively the cost, delivery and environmental protection capabilities of the apparel manufacturing factories. These results are partially consistent with previous findings by Swink, et al. (2005) and Keller, 2012. Since quality is not a competitive priority of this industry, Hypothesis $5 a$ was rejected.

\section{Conclusions, limitations and suggestions for future research}

One of the greatest challenges of the apparel manufacturing industry is finding ways to increase their competitiveness to stay in business. Managers in this industry need to know where they should focus their efforts, what is their company's current status in those areas, and which practices can help them strengthen those areas. This study was performed with data obtained from a survey to managers and engineers from a sample of multinational apparel manufacturing companies located in Central America. The main contributions of the study were the following:

- The identification of the set of process improvement practices (PIP) that are being used in Central American apparel manufacturing factories.

- $\quad$ Statistical confirmation that apparel manufacturing factories with high use of PIP also have a high manufacturing competitiveness (MC).

- Statistical confirmation of the positive effect that error detection and waste elimination PIP have in improvements in delivery time, cost and environmental protection, as well as the positive effect that time reduction PIP has in improvements in cost and environmental protection.

This study confirmed that apparel manufacturing factories with high use of PIP tend to achieve a superior MC, confirming similar findings in SME industries (Koc \& Bozdag, 2009) and in Indian industries (Vinodoh \& Joy, 2012). From the regression analysis it was found that practices related to error detection (FMEA and Jidoka) and waste elimination (5-S, Kaizen, TPM, VSM and ANDON) have a positive effect in three competitive factors: cost, environmental protection and delivery time. This means that managers seeking to improve their plant's performance on those specific manufacturing capabilities could use those practices to do it. Similarly, it was found that time reduction practices (cellular manufacturing, SOP, Kanban, AMT, SMED) have a positive effect in cost and environmental protection capabilities. 
All these results can be of great use to scholars and practitioners. For scholars these results add empirical external validation for theory regarding the competitive priorities and capabilities of apparel manufacturing industries in emerging economies and the effects of the use of specific PIP in those competitive capabilities. For practitioners, these results propose a method to assess the impact that PIP have on competitiveness in their factories and a way to measure MC so they know where to focus their improvement efforts. The study also gives evidence that the use of PIP can increase the MC of their plants. Finally, practitioners are presented with an array of PIP that have a positive effect in the competitive capabilities of this industry and that they can adopt to improve their performance and respond better to market demands.

However, it is also important to consider the limitations of the study. Although the research sample was statistically appropriate, it was relatively small and limited to apparel manufacturing factories located in Honduras. Therefore, it is suggested that for future studies the proposed method can be replicated with a larger sample and with similar factories located in more developing countries. Having a larger sample would not only add confidence to the results but will also permit the use of structural equation modelling (SEM) for a more complete analysis. Another limitation is that MC was calculated using a selfreport survey. Although this type of survey is popular in the literature, it is recommended that for future studies MC can be calculated based on specific key performance indicators (KPI) that can measure the competitive capabilities more objectively in order to improve the confidence of the results.

\section{References}

Alonso, J., Carrillo, J., and Contreras, O. (2002). "Aprendizaje tecnológico en las maquiladoras del norte de Mexico" [Technological learning in the maquiladoras in northern Mexico], Revista Frontera Norte, 14 (27), 43-82.

Alsmadi, M., Almani, A., and Jerisat, R. (2012). "A comparative analysis of lean practices in performance in the UK manufacturing and service sector firms", Total Quality Management \& Business Excellence, 23 (3-4), 381-396.

Angelis, J., Conti, R., Cooper, C., and Gill, C. (2011). "Building a highcommitment lean culture", Journal of Manufacturing Technology Management, 22 (5), 569-586.

Arora, A., Jaju, A., Kefalas, A.G., and Perenich, T. (2004). "An exploratory analysis of global managerial mindsets: a case of U.S. textile and apparel industry", Journal of International Management, 10, 393-411.

Avella, L., Fernández, E., and Vásquez, C. J. (2001). "Analysis of manufacturing strategy as an explanatory factor of competitiveness in the large Spanish industrial firm", International Journal of Production Economics, 72 (1), 139 - 157.

Avella, L., Vazquez-Bustelo, D. \& Fernandez, E. (2011). "Cumulative manufacturing capabilities: An extended model and new empirial evidence". International Journal of Production Research, 49 (3), 707-729.
Awwad, A. S., Al Khattab, A. A., and Anchor, J. R. (2013). "Competitive priorities and competitive advantage in Jordanian manufacturing", Journal of Service Science and Management, 6 (1), 69-79.

Balkwell, C. and Dickerson, K.G. (1994). "Apparel production in the Caribbean: A classic case of the new international division of labor", Clothing and Textile Research Journal, 12 (3), 6-15.

Barney, J. (1991). "Firm resources and sustained competitive advantage”, Journal of Management, 17 (1), 99-120.

BCH (2014). "Bienes para la transformación y actividades conexas 2014, expectativas 2015-2016”, available at http://www.bch.hn/ download/maquila/informe_bienest2014.pdf (accesed 12 November 2015).

Belekoukis, I., Garza-Reyes, J. A. \& Kumar, V. (2014). The impact of lean methods and tools in the operational performance of manufacturing organisations. International Journal of Production Research, 52 (18), 5346-5366.

Bohrnstedt, G. (1983). "Measurement” In P. Rossi, J. Wright, and A. Anderson (Eds)., A handbook of survey research. San Diego, CA: Academy Press.

Bortolotti, T., Boscari, S. \& Danese, P. (2015). "Successful lean implementation: Organizational culture and soft lean practices". International Journal of Production Economics, 160 182-201.

Bülbül, H., Ömürbek, N., Paksoy, T., and Bektaş, T. (2013). “An empirical investigation of advanced manufacturing technology investment patterns: Evidence from a developing country", Journal of Engineering and Technology Management, 30 (1), 136-156.

Chang, S.-C., Lin, R.-J., Chen, J.-H., and Huang, L.-H. (2005). “Manufacturing flexibility and manufacturing proactiveness: Empirical evidence from the motherboard industry", Industrial Management \& Data Systems, 105 (8), 1115-1132.

Clark, K. B. (1996). "Competing through manufacturing and the new manufacturing paradigm: Is manufacturing strategy passe?", Production and Operation Management, 5 (1), 42-58.

Cohen, J. (1988). Statistical power analysis for the behavioral science $\left(2^{\text {nd }}\right.$ ed). Hillsdale, NJ: Lawrence Earlbaum Associates.

Contreras, O. and Carrillo, J. (2012). "Local entrepreneurship within global value chains: A case study in the Mexican automotive industry", World Development, 40 (5), 1013-1023.

David, F.N. (2009). "Tables of the ordinates and probability integral of the distribution of the correlation coefficient in small samples", Cambridge: Cambridge University Press.

De Carolis, D. M. (2003). "Competencies and imitability in the pharmaceutical industry: An analysis of their relationship with firm performance", Journal of Management, 29 (1), 27-50. 
Diaz, M. S., Machuca, J. D., and Alvarez-Gil, M. J. (2003). "A view of developing patterns of investment in AMT through empirical taxonomies: new evidence", Journal of Operations Management, 21 (5), 577-606.

Fine, C. M., and Hax, A. C. (1985). "Manufacturing Strategy: A methodology and an illustration", Interfaces, 15 (6), 28-46.

Flynn, B. B., Sakakibara, S., and Schroeder, R. G. (1995). "Relationship between JIT and TQM: Practices and performance", Academy of Management Journal, 38 (5), 1325-1360.

Flynn, B. B., Schroeder, R. G., and Flynn, E. J. (1999). "World class manufacturing: An investigation of Hayes and Wheelwright's foundation", Journal of Operations Management, 17 (3), 249-269.

Fullerton, R. R., and Wempe, W. F. (2009), "Lean manufacturing, non-financial performance measures, and financial performance", International Journal of Operations and Production Management, 29 (3), 214-240.

García-Muiña, F. E., and Navas-López, J. E. (2007). "Explaining and measuring success in new business: The effect of technological capabilities on firms results", Technovation, 27 (1-2), 30-46.

García, J. L., Maldonado, A. A., Alvarado, A., Cortes, G., and Hernández, G. A. (2014). "A systematic review/survey for JIT implementation: Mexican maquiladoras as case study", Computers in Industry, 65 (4), 761-773.

Geum, Y., Cho, Y., and Park, Y. (2011). "A systematuc approach for diagnosing service failure: Service-specific FMEA and grey relational analysis approach", Mathematical and Computer Modelling, 54, 3126-3142.

Greasley, A. (2009). Operations Management (2nd ed.), Chichester: John Wiley.

Green, S.B. (1991). "How many subjects does it take to do a regression analysis?", Multivariate Behavioral Research, 26 (3), 499-510.

Green, K. W., Inman, R. A., Birou, L. M. \& Whitten, D. (2014). “Total JIT (T-JIT) and its impact on supply chain competency and organizational performance", International Journal of Production Economics, $147,125-135$.

Hana Arrfou, M., Amlus, M. H. \& Jusoh, M. S. (2016). "Assessing the mediating role of lean manufacturing practices in the relationship between TQM practices and operational performance", Journal of Scientific Research and Development, 3 (7), 44-53.

Hanson, D., Hitt, M. A., Ireland, R. D., and Hoskisson, R. E. (2012). Strategic Management: Competitiveness and Globalisation, South Melbourne: Cengage Learning Australia.

Hernández, J. C., and Vizán, A. (2013). Lean manufacturing: Conceptos, técnicas e implantación [Lean manufacturing: Concepts, Techniques and Implementation], Madrid: Escuela de Organización Industrial.
Jonsson, P. (2000). "An empirical taxonomy of advanced manufacturing technology", International Journal of Operations \& Production Management, 20 (12), 1446 - 1474.

Jun, M., Cai, S., and Shin, H. (2006). "TQM practice in maquiladora: Antecedents of employee satisfaction and loyalty", Journal of Operations Management, 24 (6), 791-812.

Keller, D. (2012, Jan 17). Balancing Cost, Quality and Delivery, Retrieved from Minitab Blog: https://www.google.com/amp/blog.minitab. com/blog/adventures-in-software-development/risk-based-testingat-minitab-using-quality-companions-fmea\%3fhs_amp=true

Khanchanapong, T., Prajogo, D., Sohal, A. S., and Cooper, B. K. (2014). "The unique and complementary effects of manufacturing technologies and lean practices on manufacturing operational performance", International Journal of Production Economics, 153 (1), 191-203.

Koc, T., and Bozdag, E. (2009). "The impact of AMT practices on firm performance in manufacturing SMEs", Robotics and ComputerIntegrated Manufacturing, 25 (2), 303-313.

Kudlác, S., Stefancová, V., and Majercák, J. (2017). "Using the Saaty Method and the FMEA Method for Evaluation of Constraints in Logistics Chain", Procedia Engineering, 187, 749-755.

Lall, S. (2001), Competitiveness, technology and skills, Cheltenham, UK: Edward Elgar Publishing.

Laohavichien, T. \& Wanarat, S. A. (2013). “Structural equation model assessment of lean manufacturing performance", International Conference on Information and Social Science (ISS). September 24-26, 2013.

Lawrence, J. L., and Hottenstein, M. P. (1995). "The relationship between JIT manufacturing and performance in Mexican plants affiliated with U.S. companies", Journal of Operations Management, 13 (1), 3-18.

Lee, K., and Choi, B. (2006). "Six sigma management activities and their influence on corporate competitiveness", Total Quality Management and Business Excellence, 17 (7), 893 - 911.

Lee, S.M., and Ebrahimpour, M. (1984). "Just-in-time production system: some requirements for implementation”, International Journal of Production Management, 4 (4), 3-15.

Leong, G. K., Snyder, D. L., and Ward, P. T. (1990). "Research in the process and content of manufacturing strategy", Omega International Journal of Management Science, 18 (2), 109-122.

Magretta, J. (2012). Understanding Michale Porter: the essential guide to competition and strategy, Boston, MA: Harvard Business Review Press.

Mendoza, J. E. (2010). "The effect of the chinese economy on Mexican maquiladora employement”, The International Trade Journal, 24 (1), $52-83$. 
Mohd Hame, N. B., Owee Kowang, T., and Chin Fei, G. (2017). "Categorization of Lean Research and Development Tools and Techniques: A Process-Based Approach", Indian Journal of Science and Technology, $10(3), 1-7$

Ndiaye, N., Razak, L.A., Nagayev, R., and Ng, A. (2018). "Demystifying small and medium enterprises' (SME) performance in emerging and developing economies", Borsa Istanbul Review, 20, 1-17.

Niebel, T. (2018). "ICT and economic growth - Comparing developing, emerging and developed countries", World Development, 104, 197-211.

Nunnally, J., and Bernstein, I. (1994). Psychometric Theory (3rd ed), New York: McGraw-Hill.

Ocampo, J.R., Hernández-Matías, J.C., and Vizán, A. (2017). “Method for estimating manufacturing competitiveness: The case of the apparel maquiladora industry in Central America”, DYNA, 84 (200), 97-106.

Oliveira, G.S., Corrêa, J.E., Balestrassi, P.P., Martins, R.A., Turrioni, J.B. (2017). "Investigation of TQM implementation: empirical study in Brazilian ISO 9001-registered SME", Total Quality Management and Business Excellence, 3363, 1-19.

Padhi, N. (2015, July 30). iSixSigma, Retrieved from The Eight Elements of TQM: http://www.isixsigma.com/methodology/total-quality-management-tqm/eight-elements-tqm/

Panwar, A., Rakesh, J., Singh, A. P., Nepal, B. \& Lyons, A. C. (2018). "The impact of lean practices on operational performance - an empirical investigation of Indian process industries". Production Planning \& Control, 29 (2), 158-169.

Pavnaskar, S.J., Gershenson, J.K., Jambekar, A.B. (2003). “Classification scheme for lean manufacturing tools", International Journal of Production Research, 41 (13), 3075-3090.

Pearce, A., Pons, D., Neitzert, T. (2018). "Implementing lean - outcomes from SME case studies", Operations Research Perspectives, 5, 94104.

Pinjala, S., Pintelon, L., and Vereecke, A. (2006). "An empirical investigation on the relationship between business and maintenance strategies", International Journal of Production Economics, 104 (1), 214-229.

Prasad, S., Tata, J., Madan, M. (2005). "Build to order supply chains in developed and developing countries", Journal of Operations Management, 23 (5), 551-568.

Putranto, K, Stewart, D., Moore, G., Diatmoko, R. (2003). "Implementing a technology strategy in developing countries: the experience of the Indonesian rolling stock industry", Technological Forecasting \& Social Change, 70 (1), 163-176.

Rostek, K. (2012). “The reference model of competitiveness factor for SME medical sector”, Economic Modelling, 29 (1), 2039 - 2048.
Salegna, G. \& Fazel, F. (1995). "An integrative framework for developing and evaluating a TQM implemenntation plan", Quality Management Journal, 3 (1), 73 - 85.

Santos-Vijande, M. L. \& Álvarez-González L. I. (2009). “TQM’s contributions to marketing implementation and firm's competitiveness", Total Quality Management \& Business Excellence, 20 (2), 171-196.

Sarache, W. A., Castrillón, O. D., and Giraldo, J. A. (2012), "Prioridades competitivas para la industria de la confección: estudio de caso" [Competitive Priorities for the clothing industry: a case study], Cuadernos de administración, 24 (43), 89-110.

Scott, G. M. (2000), "Critical technology management issues of new product development in high-tech companies", Journal of Production Innovation Management, 17 (1), 55-77.

Sharma, S. (1996), Applied Multivariate Techniques, New York: Wiley. Sitompul, C. (2012), "A supply chain planning for small and medium enterprises", Procedia Economics and Finance, 4, 384-389.

Sureerattanan, C., Napompech, K. \& Panjakhajornsak, V. (2014). "Model of leadership and the effect of lean manufacturing practices on firm performance in Thailand's auto parts industry", Research Journal of Business Management, 8 (2), 104-117.

Swamidass, P. M., \& Kotha, S. (1998). "Explaining manufacturing technology use, firm size and performance using a multidimensional view of technology". Journal of Operations Management, 17 (1), 23 - 37.

Swamidass, P.M. (2003). "Modeling the adoption rates of manufacturing technology innovation by small US manufacturers: a longitudinal investigation", Research Policy, 32 (3), 351-366.

Swink, N., Narasimhan, R., and Kim, S. W. (2005), "Manufacturing practices and strategy integration: Effects on cost efficiency, flexibility, and market-based performance", Decision Science, 36 (3), 427-457.

Swink, M., and Nair, A. (2007), "Capturing the competitive advantages of AMT: Design-manufacturing integration as a complementary asset", Journal of Operations Management, 25 (3), 736-754.

Tan, K. C., Kannan, V. R., and Narasimhan, R. (2007), “The impact of operations capability on firm performance", International Journal of Production Research, 45 (21), 5135-5156.

van Assen, M. (2018). "Lean, process improvement and customer focused performance. The moderating effect of perceived organisational context", Total Quality Management and Business, 1-18.

Vinodh, S., and Joy, D. (2012), "Structural Equation Modelling of lean manufacturing practices", International Journal of Production Research, 50 (6), 1598-1607.

Ward, P. T., McCreery, J. K., Ritzman, L. P., and Sharma, D. (1998), "Competitive priorities in operations management", Decision Science, 29 (4), 1035-1046. 
Ward, P., and Zhou, H. (2006), "Impact of information technology integration and lean/just-in-time practices on lead-time performance", Decision Science, 37 (2), 177-203.

Yang, C.-L., Lin, S.-P., Chan, Y.-h., and Sheu, C. (2010), “Mediated effect of environmental management on manufacturing competitiveness: An empirical study", International Journal of Production Economics, 123 (1), 210-220.

Yang, M.G., Hong, P., and Modi, S. B. (2011), "Impact of lean manufacturing and environmental management on business performance: An empirical study on manufacturing firms", International Journal of Production Economics, 129 (2), 251-261.

Yeung, A.C.L., Cheng, T.C.E., Kee-Hung, L. (2006). “An operational and institutional perspective in total quality management", Production and Operations Management, 15 (1), 156-170.
Yung-Ching, H., and Tsui-Hsu, T. (2006), "The impact of dynamic capabilities with market orientation and resource-based approaches of NPD project performance", Journal of American Academy of Business, 8 (1), 215-229.

Zeng, J., Phan, C.A. \& Yoshiki, M. (2015). “The impact of hard and soft quality management on quality and innovation performance: An empirical study". International Journal of Production Economics, 162, 216-226.

Zollo, M., and Winter, S. (2002), "Deliberate learning and the evolution of dynamic capabilities", Organization Science, 13 (1), 339-351. 